\title{
Chemokines in rheumatoid arthritis
}

\author{
Zoltan Szekanecz ${ }^{1,5}$, Robert M. Strieter², Steven L. Kunkel ${ }^{3}$, Alisa E. Koch ${ }^{1,4}$ \\ ${ }^{1}$ Department of Medicine, Section of Arthritis and Connective Tissue Diseases, \\ Northwestern University Medical School, Department of Medicine, 303 E. Chicago Avenue, \\ Ward Building 3-315, Chicago, IL 60611, USA \\ ${ }^{2}$ Department of Medicine, The University of Michigan Medical Center, Ann Arbor, MI 48109, USA \\ ${ }^{3}$ Department of Pathology, The University of Michigan Medical Center, Ann Arbor, MI 48109, USA \\ ${ }^{4}$ Veteran's Administration Lakeside Medical Center, Chicago, IL 60611, USA \\ ${ }^{5}$ Third Department of Medicine, University Medical School, Debrecen, Hungary
}

\section{Introduction}

Rheumatoid arthritis (RA) is a systemic chronic inflammatory disease with a prevalence of $1.8-3 \%$ of the population [20]. In RA, the synovial tissue is invaded by inflammatory cells. These leukocytes and their products play an essential role in synovitis, pannus formation and, eventually, joint destruction [20]. Cytokines are mediators involved in the inflammatory events underlying RA [15, 33]. The chemokine family consists of a number of distinct cytokines with structural homology. These proteins have potent chemotactic activity for cells of the immune system, and they appear to play a particularly important role in both the destructive and the fibrovasculoproliferative phase of RA (reviewed in $[34,35,45,62,65,71]$ ). Among cells present in the RA synovium, macrophages are a major source of chemokines [34, 35, 45]. Many of these chemokines are also involved in RA-associated angiogenesis, the formation of new blood vessels in the inflamed synovium (reviewed in [63]).

Clinical management of RA is often difficult, and includes long-term use of immunosuppressants. There are constant attempts to target specific points of the complex pathogenetic network underlying RA, including anti-cytokine therapy.

Here we give a general introduction to chemokines (Table 1), followed by an overview of the most important chemokines that may play a role in RA. The chemokine interleukin (IL)- 8 serves as prototype, since it has been studied most extensively in arthritis. We also discuss recent data on the possible role of certain chemokine receptors in RA (Table 2). We then summarize the role of chemokines in context with other cytokines present in the RA synovium. Finally, we also give an overview on the clinical importance of chemokines by summarizing experimental data on anti-chemokine targeting in arthritis. 
Table 1. Chemokine families and their most relevant representatives

$\mathrm{C}-\mathrm{X}$-C chemokines

Interleukin-8 (IL-8) ${ }^{\mathrm{a}}$

Epithelial-neutrophil activating protein-78 (ENA-78) ${ }^{\mathrm{a}}$

Growth-related gene product alpha (gro $\alpha)^{1}$

Growth-related gene product beta (gro $\beta$ )

Granulocyte chemotactic protein-2 (GCP-2)

Platelet basic protein

Connective tissue activating protein-III (CTAP-III) ${ }^{\mathrm{a}}$

Neutrophil-activating protein-2 (NAP-2)

$\beta$-Thromboglobulin ( $\beta$-TG)

Interferon- $\gamma$-inducible protein-10 (IP-10)

Platelet factor 4 (PF4)

Monokine induced by IFN- $\gamma$ (MIG)

Stromal cell-derived factor (SDF-1)

C-C chemokines

Monocyte chemoattractant protein-1 (MCP-1)

Monocyte chemoattractant protein-2 (MCP-2)

Monocyte chemoattractant protein-3 (MCP-3)

Monocyte chemoattractant protein-4 (MCP-4)

Macrophage inflammatory protein- $1 \alpha$ (MIP- $1 \alpha)^{\mathrm{a}}$

Macrophage inflammatory protein-1 $\beta$ (MIP-1 $\beta$ )

Regulated upon activation normally $\mathrm{T}$ cell expressed and secreted (RANTES) ${ }^{\mathrm{a}}$

Eotaxin

Thymus and activation-regulated chemokine (TARC)

Liver and activation-regulated chemokine (LARC)

Pulmonary and activation-regulated chemokine (PARC)

Macrophage-derived chemokine (MDC)

Human CC chemokine-1 (HCC-1)

Human CC chemokine-2 (HCC-2)

I-309

Myeloid progenitor inhibitory factor 1 (MPIF-1)

Myeloid progenitor inhibitory factor 2 (MPIF-2)

EBI-1 ligand chemokine (ELC)

Secondary lymphoid tissue chemokine (SLC)

C chemokines

Lymphotactin

$\mathrm{C}-\mathrm{X}-\mathrm{C} 3$ chemokines

${ }^{a}$ Chemokines of great importance in rheumatoid arthritis

\section{The subfamilies of chemokines}

Leukocyte chemotaxis and migration through the endothelial barrier into the inflamed synovium is crucial for the initiation and maintenance of arthritis [20,35]. The identification of chemotactic cytokines, termed chemokines, led to the better understanding of this process. Monomeric chemokines have a molecular mass of less than 10 kilodaltons $[45,65,71]$. 
Table 2. Chemokine receptors and their ligands ${ }^{a}$

\begin{tabular}{ll}
\hline Chemokine receptor & Ligand \\
\hline C-X-C chemokine receptors & \\
CXCR 1 & IL-8 \\
CXCR 2 & IL-8, ENA-78, gro, NAP-2 \\
CXCR 3 & IP-10, MIG \\
CXCR 4 (fusin) & SDF-1 \\
DARC (Duffy antigen receptor for chemokines) & IL-8, ENA-78, gro, NAP-2 \\
C-C chemokine receptors & \\
CCR 1 & \\
CCR 2 & MCP-2, MCP-3, MIP-1 $\alpha$, RANTES, HCC-2 \\
CCR 3 & MCP-1, MCP-2, MCP-3, MCP-4 \\
CCR 4 & MCP-3, MCP-4, Eotaxin, RANTES, HCC-2 \\
CCR 5 & TARC \\
CCR 6 & MIP-1 $\alpha$, MIP-1 $\beta$, RANTES \\
CCR 7 & LARC \\
CCR 8 & ELC \\
CCR 10 & I-309 \\
\hline
\end{tabular}

a See Table 1 for abbreviations

${ }^{b}$ Major receptor for the angiogenic ELR-containing chemokines

In the original description of these chemotactic mediators, chemokines have been classified into two distinct supergene families based on their structural homology regarding the location of two of four conserved cysteine residues. In $C-X-C$ chemokines, also known as $\alpha$ chemokines, these two conserved cysteines are separated by one unconserved amino acid and hence the designation " $\mathrm{C}-\mathrm{X}-\mathrm{C}$ " (reviewed in [71]). In contrast, the $C$ - $C$ chemokine ( $\beta$ chemokine) subfamily members have adjacent conserved cysteine residues (reviewed in [65]). Both subfamilies include a number of mediators; however, only some of these have been shown to play a role in the pathogenesis of inflammatory arthritis.

Recently two additional chemokine families termed $C$ chemokines and $C-X-C 3$ chemokines have been described based on the unique position of cysteine residues $[2$, 40]. The former family contains only one member termed lymphotactin [40], while the $\mathrm{C}-\mathrm{X}-\mathrm{C} 3$ family consists of members expressed on cytokine-activated endothelia, but, in contrast to $\mathrm{C}-\mathrm{X}-\mathrm{C}$ and $\mathrm{C}-\mathrm{C}$ chemokines, not on peripheral blood leukocytes [2]. We have not found any information on these new chemokine families in association with arthritis.

\section{$\mathrm{C}-\mathrm{X}-\mathrm{C}(\alpha)$ chemokines}

This chemokine subfamily includes, among many others, IL-8, epithelial-neutrophil activating protein (ENA)-78, growth-regulated oncogene $\alpha$ (gro $\alpha$ ) and $\beta$ (gro $\beta$ ), connective tissue activating peptide (CTAP)-III, platelet factor-4 (PF4), and interferon- $\gamma$ inducible protein (IP-10) (reviewed in [71]) (Table 1). C-X-C chemokines are mostly neutrophil chemotactic factors, although PF4 and IP-10 may also chemoattract monocytes and T lymphocytes [71]. 
Table 3. Pro-angiogenic and anti-angiogenic $\mathrm{C}-\mathrm{X}-\mathrm{C}$ chemokines

\begin{tabular}{ll}
\hline Pro-angiogenic & Anti-angiogenic \\
\hline IL-8 & IP-10 \\
ENA-78 & PF4 \\
gro $\alpha$ & MTG \\
gro $\beta$ & \\
CTAP-III & \\
\hline
\end{tabular}

C-X-C chemokines mediate a number of mechanisms underlying inflammation. For example, IL-8 stimulates neutrophil chemotaxis and haptotaxis, $\beta 2$ integrin expression on, and L-selectin shedding from, leukocytes, adhesion to extracellular matrix components, cytoskeleton reorganization and actin polymerization, neutrophil degranulation, matrix metalloproteinase production, the release of leukotrienes and plateletactivating factor, the respiratory burst and phagocytosis (reviewed in [71]).

Some $\mathrm{C}-\mathrm{X}-\mathrm{C}$ chemokines promote, while others inhibit angiogenesis $[62,63]$ (Table 3). It has been suggested recently that the ELR (glutamyl-leucyl-arginyl) motif found in a number of C-X-C chemokines, such as IL-8, ENA-78, gro $\alpha$ and CTAP-III, is responsible for the angiogenic activity of these chemokines [62, 63]. In contrast, $\mathrm{C}-\mathrm{X}-\mathrm{C}$ chemokines lacking the ELR motif, such as PF4 and IP-10 are potent angiostatic mediators $[62,63]$. Endothelial cells express receptors for angiogenic chemokines, such as IL-8, which is important for the initiation and maintenance of chemokine-mediated neovascularization [55, 59].

\section{C-C ( $\beta$ ) chemokines}

The C-C chemokine subfamily consists of at least 20 members. The most relevant $\mathrm{C}-\mathrm{C}$ chemokines for RA are monocyte chemoattractant protein (MCP)-1, macrophage inflammatory proteins (MIP)- $1 \alpha$ and $-1 \beta$, as well as the chemokine termed Regulated upon Activation Normally T cell Expressed and Secreted (RANTES) (Table 1). These chemokines are essentially monocyte chemoattractants, but they may also be chemotactic for T cells, NK cells, basophils and eosinophils (reviewed in [65]).

\section{C-X-C chemokines in RA}

We and others have shown that among $\mathrm{C}-\mathrm{X}-\mathrm{C}$ chemokines described above, IL-8, ENA-78, groo, and CTAP-III likely play a role in the pathogenesis of RA. IP-10, PF4 and possibly gro $\beta$ seem to be less important in RA $[21,43,75]$.

\section{IL-8}

\section{Detection of $I L-8$ in $R A$}

IL-8, a C-X-C chemokine (Table 1), has been detected in the synovial fluids, synovial tissues and, unlike a number of other cytokines, in the sera of RA patients $[26,60]$. 


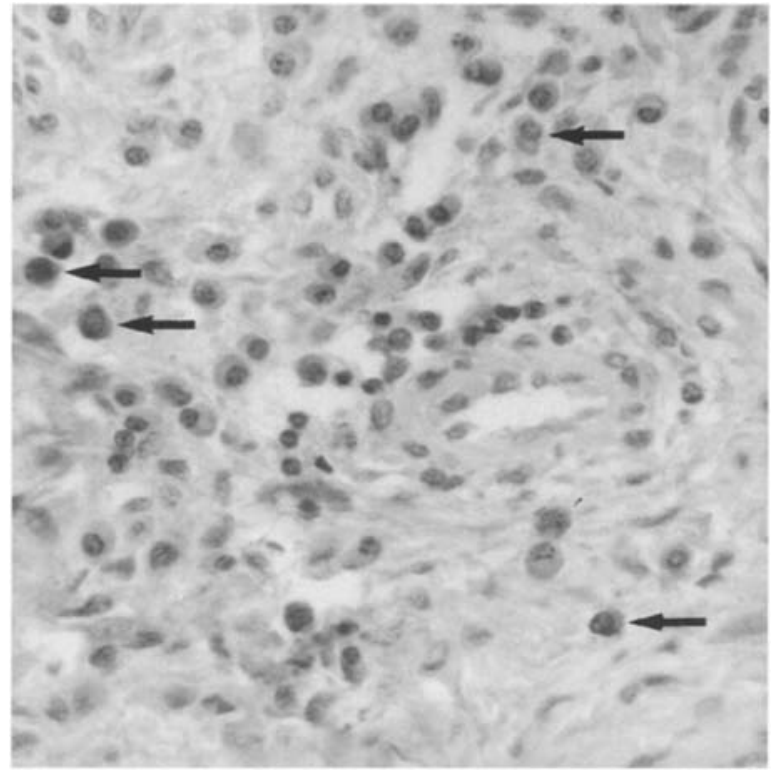

Fig. 1. IL-8 expression in theumatoid synovial macrophages. (Immunoperoxidase histochemistry: $\times 330)$

Several investigators, including our group, found increased levels of IL-8 in RA synovial fluids in comparison to other rheumatic diseases, such as osteoarthritis (OA) or gonococcal arthritis $[11,21,26,46,49,60]$. RA synovial fluid $\mathrm{LL}-8$ levels were generally in the range of $1-18 \mathrm{ng} / \mathrm{ml}$. Apart from the presence of antigenic IL- 8 in these RA synovial fluid samples, we demonstrated that this IL- 8 was bioactive. Immunoneutralization of IL-8 resulted in a significant down-regulation of RA synovial fluid-mediated neutrophil chemotactic activity in vitro [26].

IL-8 was also detectable in the sera of RA patients. Moreover, serum IL- 8 levels showed significant positive correlation with IL-8 concentrations in synovial fluids [26]. Thus, measuring serum IL-8 may reflect intra-articular IL- 8 levels, and it may serve as a useful tool in monitoring the escalation of inflammation within the joint.

In RA synovial tissues, a number of cell types appear to produce IL-8 in situ (Fig. 1). Using immunohistochemistry, we found immunoreactive IL-8 in interstitial macrophages, as well as in the synovial lining layer, which also contains macrophage-derived cells [26]. Others found a similar expression pattern with an additional endothelial reactivity [9]. These results suggest that the macrophage is among the principal producers of IL-8 in the synovial tissue.

\section{Producers of IL-8 in the RA synovium}

We have shown that isolated synovial macrophages produce abundant $I L-8$ mRNA and protein in vitro [26]. These cells, unlike synovial tissue fibroblasts, constitutively secrete IL-8. As additional stimuli such as IL-1 cannot further increase IL-8 production, it is likely that macrophages are maximally stimulated in vivo to produce IL-8. Freshly isolated RA synovial fluid mononuclear cells synthesize more IL-8 mRNA and protein than do cells derived from the peripheral blood of the same patients [22]. 
In contrast to macrophages, synovial fibroblasts produce IL- 8 in vitro in the presence of agonists including $\mathrm{IL}-1 \alpha$, IL-1 $\beta$, tumor necrosis factor (TNF)- $\alpha$ and lipopolysaccharide (LPS) $[3,22,52]$. IL- $1 \beta$ and TNF- $\alpha$ act synergistically in the stimulation of IL-8 secretion by RA synovial fibroblasts [52]. L-1 and TNF- $\alpha$ may act by different mechanisms, as inhibition of protein synthesis resulted in superinduction of IL-8 mRNA in IL-1, but not TNF- $\alpha$-stimulated fibroblasts [3]. Furthermore, IL-4 further enhanced, while interferon- $\gamma$ inhibited both IL-1- and TNF- $\alpha$-mediated IL- 8 synthesis [51]. These data suggest that, unlike macrophages, synovial fibroblasts require exogenous stimulation to produce IL-8.

Cartilage explants, as well as isolated chondrocytes are also capable of releasing $\mathrm{IL}-8$ in vitro upon exposure to IL-1 $[39,53]$. In addition, $\mathrm{IL}-8$ synthesis by these cells requires the continuous presence of IL-1 [53].

In contrast to many other cytokines, including IL-1, -2, -3, -4, -7, granulocytemacrophage (GM-CSF) and granulocyte colony-stimulating factors (G-CSF) or TNF- $\alpha$ and $-\beta$, IL- 8 is increased in bone marrow aspirates from RA patients in comparison with normal subjects [64]. Moreover, IL-8 production by bone marrow cells correlated with the degree of synovitis in these patients.

\section{Functional aspects of $I L-8$ in $R A$}

Early investigations showed that human synovial cells stimulated with IL-1 in vitro released a then-unknown low molecular weight factor, which stimulated neutrophil locomotion $[72,73]$. It is likely that these investigators noted the effects of IL-8 or one of the related chemokines.

IL- 8 induces synovial inflammation, as determined by a single intra-articular injection of recombinant IL-8 into the rabbit knee joint [11]. Arthritis indicated by joint erythema and limp after $4 \mathrm{~h}$ post injection was associated with an early entry of neutrophils into the synovial fluid, followed by the accumulation of mononuclear cells $8 \mathrm{~h}$ after injection. In the synovial tissue, neutrophil infiltration of the synovial lining and the perivascular area observed at $4 \mathrm{~h}$ post $\Pi \mathrm{L}-8$ injection was followed by the proliferation of synovial lining cells and the thickening of the lining layer at $24 \mathrm{~h}$ post IL- 8 injection. This multilayered lining layer was composed of macrophages and fibroblasts, and this histological picture was reminiscent of the human RA synovium. This study indicates that, in principal, IL- 8 can induce joint inflammation and synovial changes similar to those found in RA patients.

The onset and development of arthritis can also be studied by chemokine cDNA transfer to animal models of RA. Studies employing IL-8 gene transfer are still in early phases of development. Rabbit IL-8 cDNA can be transduced into rabbit synoviocytes using replication defective adenovirus [7]. This technique may help to study the effects of local and prolonged expression of IL-8 in an experimental model of arthritis.

IL- 8 may regulate adhesion molecule expression on leukocytes in RA. Synovial fluid IL- 8 levels have been correlated with $\beta 2$ integrin expression on synovial fluid neutrophils in RA patients [8].

We have described a novel function for IL-8 as a mediator of angiogenesis [28] (Table 3). IL-8 is both chemotactic and mitogenic for endothelial cells in vitro and it is a potent angiogenic factor in in vivo models for angiogenesis. As anti-IL-8 antibody and IL- 8 antisense oligonucleotides inhibited angiogenesis induced by peripheral blood monocytes and synovial tissue macrophages, IL-8 accounts for a significant por- 
tion of monocyte/macrophage-derived angiogenic activity. As described above, IL-8 contains the ELR motif, which may be responsible for its angiogenic effects found by us and other investigators $[62,63,71]$. Endothelial cells express receptors for IL-8 $[55,59]$. Thus, IL-8 is an important chemotactic cytokine which not only participates in the inflammatory events, but also in new vessel formation underlying the parthogenesis of RA.

\section{ENA-78}

ENA-78 is a member of the C-X-C chemokine family. ENA-78 is a potent chemotactic factor for neutrophils and promotes neovascularization $[63,70,71]$ (Tables 1 and 3 ).

We have detected increased levels of ENA-78 in RA in comparison to OA synovial fluids [30]. Both RA synovial fluid mononuclear cells and synovial tissue fibroblasts produce ENA-78. ENA-78 synthesis by fibroblasts is augmented by TNF- $\alpha$ pre-treatment. Within the synovial tissue, the main cellular source of this chemokine was the synovial lining cell layer, followed by interstitial macrophages, endothelial cells and fibroblasts. We found increased amounts of antigenic ENA-78 in the synovial tissues and sera from RA patients compared to normal subjects. Thus, for diagnostic purposes, ENA-78 can be readily measured in serum samples. ENA-78 is a very abundant protein, with mean levels being approximately 15 times higher than mean IL-8 levels in RA synovial fluids. Thus, like IL-8, a major role of ENA-78 in RA appears to be the recruitment of neutrophils.

We have recently studied the temporal expression of ENA-78 in the sera and joint homogenates of rats with adjuvant-induced arthritis, an animal model for RA (Halloran et al., submitted). Arthritis was induced by a single injection of Mycobacterium butyricum and Freund's adjuvant. Almost all animals developed arthritis by day 14 postadjuvant injection. Using an ELISA assay, we found significantly increased levels of antigenic ENA-78 in the sera of arthritic rats in comparison to sham-injected controls. This difference was first seen at day 7 post-adjuvant injection and serum levels of this chemokine continued to increase as arthritis developed. ENA-78 levels in ankle joint homogenates were increased in arthritic rats later in the development of the disease by day 18 post-adjuvant injection, compared to control rats. Expression of ENA-78 in both the sera and joint homogenates correlated with the progression of joint inflammation in arthritic animals. Thus, the increase in ENA-78 production in the sera and joints of rats may be important in the development of arthritis.

\section{Gro $\alpha$ and gro $\beta$}

Growth-related gene products (gro) $\alpha$ and $\beta$ are also members of the C-X-C chemokine subfamily $[63,71]$. Both proteins stimulate the growth of fibroblasts, chemoattract neutrophils and stimulate angiogenesis $[63,71]$ (Tables 1 and 3). Gro $\alpha$ may also be involved in repair of the damaged joint, as this chemokine perpetuates collagen loss by inhibiting RA synovial fibroblast collagen production [67].

Regarding gro $\alpha$ production in RA, we and others have found that synovial fluid neutrophils and mononuclear cells, isolated synovial tissue fibroblasts and articular chondrocytes produce gro $\alpha \mathrm{mRNA}$ and protein $[3,17,22,32,53]$. The synthesis of gro $\alpha$ by RA synovial tissue fibroblasts could be stimulated by IL- $1 \alpha$, IL-1 $\beta$ or TNF- $\alpha$. 
Groo production by RA synovial fluid mononucler cells was further increased upon cell activation with LPS or phytohemagglutinin $[22,32]$. Others reported an increased gro mRNA expression in RA synovial fluid mononuclear cells in comparison to mononuclear cells in peripheral blood from the same patients as well as from normal subjects [22].

We detected significantly increased synovial fluid concentrations of groo in RA in comparison to OA or other forms of arthritis. In addition, the serum level of this chemokine was also higher in RA patients than in normal subjects. In the synovial tissue, lining cells expressed more gro $\alpha$ in RA than in OA patients or normal individuals. There was an increased expression of this chemokine in RA in comparison to OA subsynovial macrophages [32].

One group recently examined the synovial production of gro $\alpha$ and gro $\beta$ [21]. Curiously, these authors found that the majority of synovial fibroblast lines derived from OA or other non-inflammatory synovia showed a relative increase in the constitutive expression of gro $\alpha$ and groß when compared to fibroblasts from RA synovia. Moreover, these authors, in contrast to the findings of many other investigators, were also unable to detect IL- 8 in any synovial fibroblast lines they examined by polymerase chain reaction, even upon stimulation with IL-1 or TNF- $\alpha$. It remains unclear whether the discordant results are due to technical differences between studies. It is still possible that gro $\alpha$ and gro $\beta$ are produced in different quantities and may play a differential role in RA.

Comparison of the relative role of IL-8, ENA-78 and groo in RA

Since synovial fluids from RA patients have been shown to produce significant amounts of immunoreactive and bioactive IL-8, ENA-78 and groo, it may be important to know which of these chemokines plays the greatest role in leukocyte emigration into the joint. We simultaneously immunodepleted RA synovial fluids of L-8, ENA78 and gro $\alpha$, and measured the chemotactic response of normal neutrophils to these synovial fluids [32]. In our study, IL-8, ENA-78 and gro $\alpha$ accounted for $36 \%, 34 \%$ and $28 \%$ of the chemotactic activity, respectively. These results suggest that all three chemokines are important in neutrophil recruitment into the RA joint, with IL- 8 accounting for slightly more of the neutrophil chemotactic activity than the other two chemokines. Certainly, other functional studies are needed to determine the relative importance of these and other chemokines in various pathogenic mechanisms in RA.

\section{CTAP-III}

CTAP-III is a human platelet $\alpha$-granule-derived growth factor, which is more than 100 -times as abundant as other growth factors in plasma [6]. CTAP-III, as well as $\beta$ thromboglobulin ( $\beta \mathrm{TG}$ ) and neutrophil-activating protein (NAP)-2 are $\mathrm{NH}_{2}$-truncated cleavage products of platelet basic protein $[63,71]$. CTAP-III stimulates endothelial chemotaxis and it is involved in angiogenesis $[62,63]$ (Tables 1 and 3). CTAP-III affects many aspects of connective tissue metabolism including the stimulation of DNA, hyaluronic acid, sulfated glycosaminoglycan chain, proteoglycan monomer, and proteoglycan core protein synthesis in human synovial fibroblast cultures $[5,6]$. 
Plasma of RA patients contains elevated level of CTAP-III but not $\beta$ TG or NAP-2 [6]. This chemokine was also detected in RA and OA synovial tissue extracts [5].

\section{IP-10 and PF4}

These C-X-C chemokines, unlike others described above, chemoattract monocytes and $T$ cells rather than neutrophils $[34,71]$. IP-10 and PF4 do not contain the ELR domain in their structure and have been shown to inhibit neovascularization [62,63].

Very little IP-10 has been detected in the sera of RA patients [43]. A peptide sequence from PF4 inhibited murine type II collagen-induced arthritis, a representative model for RA [75]. Thus, these two mediators, in contrast to other C-X-C chemokines discussed above, may be suppressors of arthritis-associated inflammatory and angiogenic mechanisms.

\section{C-C chemokines in RA}

MCP-1

MCP-1 chemoattracts monocytes, T cells, NK cells and basophils [65]. Although there is little evidence for the role of MCP-1 in angiogenesis, MCP- 1 mRNA expression is increased in growing hemangiomas and vascular malformations [23].

We and others have shown elevated levels of MCP-1 in synovial fluids from RA compared to OA patients $[1,27]$. RA synovial fibroblasts produce $\mathrm{MCP}-1$ in response to IL-1 $\alpha$, IL-1 $\beta$, TNF- $\alpha$ or interferon- $\gamma$, while articular chondrocytes secrete MCP-1 upon stimulation by IL- $1 \beta$, TNF- $\alpha$ or transforming growth factor (TGF)- $\beta[19,22,68$, 69]. Mononuclear cells freshly isolated from RA synovial fluids produced more MCP1 than cells from the peripheral blood of the same patients [22]. In the RA synovial tissue, interstitial macrophages are the major source of MCP-1 [27].

The main function of MCP-1 in the joint may be the recruitment of macrophages, since injection of MCP-1 into rabbit joints resulted in marked infiltration of macrophages into the synovial tissue [1].

\section{MIP- $1 \alpha$ and MIP-1 $\beta$}

MIP-1 is a term applied originally to LPS-stimulated murine macrophage conditioned medium containing two distinct molecules, MIP-1 $\alpha$ and MIP-1 $\beta$, that copurified [74]. The human equivalents for these chemokines have recently been characterized $[57$, 65]. Murine MIP- $1 \alpha$ and $\beta$ have $60 \%$ peptide identity and are $70 \%$ homologous to their human counterparts [74]. Despite their structural homology, their function in inflammation including arthritis appears to be rather different.

MIP- $1 \alpha$ is chemotactic for monocytes, T, B and NK cells, basophils and eosinophils $[65,66]$. In mice, MIP- $1 \alpha$, but not MIP-1 $\beta$ stimulates the secretion of IL$1 \beta$, TNF- $\alpha$ or IL- 6 by macrophages $[14,41]$.

We found increased levels of MIP- $1 \alpha$ in RA in comparison to OA synovial fluids [29]. Synovial fluid MIP-1 $\alpha$ was bioactive and accounted for about $36 \%$ of synovial fluid-derived chemotactic activity for monocytes. We and others reported that synovial 
fluid mononuclear cells and synovial tissue fibroblasts produce MIP- $1 \alpha$ mRNA and protein $[22,29]$. The production of this chemokine by fibroblasts could be further stimulated by IL- $1 \alpha$ and TNF- $\alpha$. Like MCP-1, the main producers of MIP- $1 \alpha$ in RA synovial tissue are macrophages and fibroblasts. Thus, MIP- $1 \alpha$ appears to be a major factor facilitating the accumulation of macrophages in the RA joint.

MIP-1 $\beta$ is a monocyte, $T$ and NK cell chemoattractant [65]. Interestingly, in contrast to many other chemokines we have examined, MIP-1 $\beta$ concentration was significantly increased in synovial fluids from patients with OA in comparison to RA [31]. There is relatively little MIP-1 $\beta$ protein in RA synovial fluids [31], although others detected MIP-1 $\beta$ mRNA in T cells isolated from RA peripheral blood or synovial fluid [54]. In our hands, this chemokine accounted for $28 \%$ of synovial fluid-induced chemotactic activity for monocytes in OA. Fibroblasts derived from OA synovial tissues did not constitutively produce MIP-1 $\beta$. However, TNF- $\alpha$, IL- $1 \beta$ or LPS treatment of these cells resulted in MIP-1 $\beta$ synthesis. In the OA synovial tissue, synovial lining cells, vascular endothelium, smooth muscle cells and a minority of macrophages expressed MIP-1 $\beta$ [31]. Thus, MIP-1 $\beta$ appears to be a chemokine, which, in contrast to most other chemokines, may play a role in leukocyte recruitment into the OA, rather than RA joint.

\section{RANTES}

RANTES is a chemotactic factor for monocytes, memory T lymphocytes, NK cells, eosinophils and basophils $[58,65]$. RA synovial fibroblasts produce RANTES mRNA upon stimulation by TNF- $\alpha$, IL-1 $\alpha$ or IL- $1 \beta[22,51]$. These effects of TNF- $\alpha$ or IL- $1 \beta$ on RANTES mRNA expression can be further increased by interferon- $\gamma$, but downregulated by IL-4 [51]. RANTES mRNA has also been detected in RA peripheral blood and synovial fluid $T$ cells, as well as in sites of extensive lymphocytic infiltration in RA synovial tissues [54].

\section{Chemokine receptors in $\mathrm{RA}$}

There are a number of known receptors for $\mathrm{C}-\mathrm{X}-\mathrm{C}$ and $\mathrm{C}-\mathrm{C}$ chemokines abbreviated as "CXCR" and "CCR", respectively. These receptors exhibit a nonspecific affinity for their chemokine ligands (Table 2). It has been suggested recently that these chemokine receptors may play a different role in various inflammatory reactions. For example, CCR3 is expressed by lymphocytes exhibiting the Th2, but not the Th1 phenotype. It is known that lymphocytes expressing the Th2 phenotype are mostly involved in humoral immunity. Accordingly, CCR3 is highly expressed in allergic lymphocytic infiltrates. In contrast, CCR5 is present on most Th1, but not on Th2-type lymphocytes. Th1-type cells play an important role in cellular immunity so it is not surprising that CCR5 has been detected in RA synovial fluids and tissues. CXCR3 is present on both Th1- and Th2-type cells, and this chemokine receptor is expressed in both allergic and synovial infiltrates [38]. Both CCR5 and CXCR3 show preferential expression on memory $\mathrm{T}$ cells showing the $\mathrm{CD} 45 \mathrm{RO}^{+}$phenotype [48].

There is relatively few data available on the possible role of chemokine receptors in RA. Among CXCR, CXCR3, while among CCR, CCR5 show strong expression on RA synovial fluid T lymphocytes, as well as in T cell-rich areas of RA synovial tissues 
$[38,48]$. Among chemokines listed in Table 1, the main ligand for CXCR3 is IP-10, while that for CCR5 is MIP-1 $\alpha$, MIP-1 $\beta$ and RANTES [48] (Table 2).

Regarding the possible role of chemokine receptors in angiogenesis, a number of these receptors may be detected on endothelial cells, thus playing a role in chemokinederived angiogenesis. The role of endothelial IL-8 receptors is discussed above [55, 59]. There is a growing body of evidence that CXCR 2 may be the most important endothelial receptor for ELR-containing angiogenic CXC chemokines: CXCR2 is a major receptor for these chemokines $[59,63,71]$. C-X-C chemokines, such as IL-8 and NAP-2, bind to endothelial cells [59].

\section{Cytokine-chemokine interactions in the RA synovium}

A regulatory network of pro-inflammatory cytokines, such as TNF- $\alpha$ and IL-1 $\beta$, and chemokines exists in the inflamed synovium of RA patients [15, 33, 34]. Both TNF- $\alpha$ and $I L-1 \beta$ are abundantly produced in the RA joint $[15,33]$. Monocytes/macrophages in the RA synovial fluid or synovial tissue constitutively express most chemokines, including IL-8 [26], ENA-78 [29], gro $\alpha$ [32], MCP-1 [27] and MIP-1 $\alpha$ [29]. In contrast to mononuclear cells, resting synovial fibroblasts and articular chondrocytes produce only small amounts of chemokines. However, TNF- $\alpha, \mathrm{L}-1 \alpha$ or IL- $1 \beta$ stimulate RA synovial fibroblasts to secrete IL-8 [3, 22, 52], ENA-78 [30], gro $\alpha[22,32]$, MCP-1 $[19,22,68,69], \mathrm{MIP}-1 \alpha[22,29]$ and RANTES [22, 51]. Interferon- $\gamma$ further enhances cytokine-mediated MCP-1 [19, 69] or RANTES production [51]. TNF- $\alpha$, IL-1 $\beta$ or TGF- $\beta$ trigger MCP-1 synthesis in RA articular chondrocytes [68]. We have described similar interactions between cytokines and MIP-1 $\beta$ in the OA synovium [31]. As evaluated using various protein kinase $C$ inhibitors, this enzyme is involved in cytokine-induced IL-8, MCP-1 and RANTES synthesis by cultured human synovial fibroblasts [24].

The synovial microenvironment containing a mixture of various regulatory cytokines may influence the production of C-X-C and C-C chemokines and, thus, the outcome of synovial inflammation. Interestingly, TNF- $\alpha$ - or IL-1 $\beta$-mediated IL- 8 synthesis by RA synovial fibroblasts is up-regulated by IL- 4 but inhibited by interferon- $\gamma$. In contrast, cytokine-dependent RANTES production by the same cells is decreased by IL-4 but stimulated by interferon- $\gamma$ [51]. Interferon- $\gamma$ is mostly produced by Th1-type lymphocytes, while IL- 4 is secreted by Th 2 cells. The major differences between Th1 and Th2 cells are discussed above. These data suggest that the type of cellular infiltrate, namely the dominance of Th1 or Th2 type lymphocytes, as well as their characteristic cytokine production, may result in a differential local chemokine pattern.

There is also an inverse relationship between MIP-1 $\alpha$ and cytokines, at least in the case of murine macrophages $[14,41]$. MIP-1 $\alpha$ stimulates the synthesis of IL-1 $\alpha$, TNF$\alpha$ or IL- 6 in these cells, suggesting a positive feedback mechanism between MIP-1 $\alpha$ and these cytokines.

These two-way interactions may be important for the perpetuation of inflammatory mediator production within the inflamed synovium. In addition, not only direct chemokine targeting, but also suppressing the production of pro-inflammatory cytokines may be useful for controlling chemokine-mediated leukocyte ingress into the RA joint. 


\section{Clinical significance of chemokine studies in RA}

Relationship between chemokine production and clinical markers of disease activity in RA

Measuring chemokine production in the sera of RA patients may be useful for monitoring the disease course. Again, most investigations in this regard have been carried out on IL-8.

It is difficult to find a consistent correlation between synovial fluid IL-8 levels and disease activity in RA. One group found a direct correlation between RA synovial fluid IL-8 concentration and joint leukocyte numbers or plasma $\mathrm{C}$ reactive protein levels [46]. Others were unable to correlate synovial fluid IL-8 levels and disease markers, such as synovial fluid leukocyte counts, erythrocyte sedimentation rate or $\mathrm{C}$ reactive protein levels $[4,49]$. This controversy may be due to several factors, including the small number of patients examined in most studies or the insensitivity of most conventional disease markers.

In another study, the possible role of IL-8 as an autoantigen in RA was suggested [47]. These investigators detected anti-IL- 8 autoantibodies in the sera of RA patients and anti-IL- 8 concentrations also correlated with disease activity. Thus, serum anti-IL8 may provide a useful diagnostic marker for disease activity in RA.

Other C-X-C chemokines, such as ENA-78 [30], groo [32] or CTAP-III [6] could also be readily measured and found in increased quantities in the sera of RA patients in comparison to normal controls. Thus, measuring the serum level of these chemokines may also closely reflect the inflammatory processes underlying RA.

\section{Chemokine targeting strategies in RA}

Chemokine production in the RA joint can be influenced in a number of ways. Nonspecific strategies include the use of anti-inflammatory drugs, which, apart from many other mechanisms of action, also affect chemokine production. Alternatively, as proinflammatory cytokines, mainly TNF- $\alpha$ and IL- $1 \beta$, stimulate the production of most chemokines by RA synovial fibroblasts or macrophages, the use of cytokine antagonists, anti-cytokine antibodies or soluble cytokine receptors may also down-regulate chemokine synthesis. Most of these approaches have already been tried in RA. Finally, preliminary studies using antibodies to chemokines and chemokine inhibitors carried out in animal models of RA suggest that direct, specific chemokine targeting may also be available in the near future.

\section{Effects of anti-inflammatory agents on chemokines}

IL-8 production may be modulated by a number of immune modulators currently used in the therapy of RA or other inflammatory arthritides. Among the most potent suppressors of IL-8 production are corticosteroids. RA synovial fluid mononuclear cell production of IL-8 was inhibited by dexamethasone [60]. Dexamethasone also suppressed the production of IL-8 by RA synovial fibroblasts by $60-80 \%$ [37]. These authors also found that when RA patients were given intra-articular betamethasone, their synovial fluid mononuclear cells exhibited decreased spontaneous and LPS-dependent 
release of IL-8. Suppressed IL-8 synthesis was accompanied by a significant decrease leukocyte and neutrophil counts. Pulse corticosteroid therapy suppressed synovial fluid IL-8 levels, as well as IL-8 expression in the synovial tissue lining layer in RA patients [76]. These results suggest that IL-8 production by a number of synovial cells may by modified clinically by anti-rheumatic drugs, such as corticosteroids. Glucocorticoids bind to intracellular receptors that recognize glucocorticoid-responsive elements in the promoter regions of genes. It may be that glucocorticoids act in this way to modulate chemokine gene expression.

In contrast to the effects observed with corticosteroids, non-steroidal anti-inflammatory drugs or disease modifying agents had little effect on IL-8 synthesis. For example, indomethacin treatment of RA synovial fluid mononuclear cells or synovial fibroblasts did not decrease IL-8 synthesis in vitro [37,60]. Other compounds such as piroxicam, naproxen, and tiaprofenic acid were also unable to inhibit IL-8 production by RA synovial fibroblasts. Sodium thiomalate inhibited RA synovial fibroblast IL-8 production only in suboptimally stimulated cells in vitro [37]. Methotrexate was also found to be ineffective in suppressing IL-8 production by fibroblasts [37], although in a recent study it decreased IL- 8 secretion by RA peripheral blood mononuclear cells in response to LPS [61].

Like IL-8, MCP-1 production can be altered by anti-rheumatic drugs and immune modulators. Dexamethasone and, to a much lesser extent, gold sodium thiomalate, inhibited the production of MCP-1 by RA synovial fibroblasts [37]. Dexamethasone blunted the induction of MCP-1 expression by IL-1 in human articular chondrocytes [68]. Again, methotrexate and nonsteroidal anti-inflammatory compounds were inactive in reducing MCP-1 production by RA fibroblasts or mononuclear cells [37, 61].

These data suggest that part of the anti-rheumatic action of corticosteroids, but not that of nonsteroidal anti-inflammatory drugs or disease-modifying agents is due to the inhibition of IL-8 and MCP-1 production and, thus, the prevention of leukocyte accumulation in the inflamed joint.

TNF- $\alpha$ induces chemokine production in part via generation of reactive oxygen intermediates. Antioxidants, such as $N$-acetyl-L-cysteine and 2-oxothiazolidine-4-carboxylate, suppressed TNF- $\gamma$-induced IL-8 and MCP-1 mRNA synthesis in isolated human synovial cells [56]. These antioxidants may be useful in inhibiting chemokine production in RA.

\section{Specific inhibition of TNF- $\alpha$ and IL-1 $\beta$ synthesis in the RA joint}

The suppression of pro-inflammatory cytokine production may also block the synthesis of cytokine-dependent chemokines. There are several ongoing studies using anticytokine monoclonal antibodies, soluble cytokine receptors, cytokine receptor antagonists or gene therapy conducted in RA patients. As these anti-cytokine trials are discussed elsewhere in this issue, we briefly mention the most relevant ones. Engineered anti-TNF- $\alpha$ monoclonal antibodies gave the best results (reviewed in $[16,50]$ ), but recombinant, soluble TNF- $\alpha$ [42] and IL-1 receptors [10], as well as IL-1 receptor antagonist protein (IL-1ra or IRAP) [36] have been tried in refractory RA. Somatic gene tranfer using a cDNA expression vector carrying human IL-1ra cDNA has been developed and approved for use in RA patients not responding to conventional treatment [12, 13].

In summary, although we have not found any data directly showing the effects of any mentioned therapies on chemokine production, it is possible that by inhibiting the 
effects of TNF- $\alpha$ or $I L-1 \beta$ one may mitigate cytokine-induced chemokine secretion. Thus, efforts aimed at interrupting the cytokine network involving chemokine production may be beneficial in the therapy of RA.

\section{Direct chemokine targeting}

The inflammatory action of chemokines may be directly suppressed using specific antibodies or other inhibitors. As described above, in our hands, antibodies to IL-8, ENA78 and gro $\alpha$ partially neutralized RA synovial fluid-derived chemotactic activity for neutrophils in vitro [32]. We have used neutralizing anti-ENA-78 antibody to treat rats with adjuvant-induced arthritis, a model for RA (Halloran et al., submitted). AntiENA-78 administered intravenously prior to the onset of arthritis attenuated the severity of the disease as determined by joint circumference measurements. In addition, anti-ENA-78 significantly reduced the number of IL-1 $\beta$-immunoreactive cells in the synovial lining layer, indicating the possible role of ENA-78 in the maintenance of cytokine production in the synovium. This antibody was unable to influence the disease course when injected during the development of arthritis. These data suggest that antichemokine antibodies may inhibit the progression of arthritis.

Other anti-chemokine antibodies have also been tried in arthritis models. Passive immunization with anti-MIP- $1 \alpha$ delayed the onset and reduced the severity of type II collagen-induced arthritis in mice $[25,35]$. A neutralizing monoclonal antibody to MCP-1 reduced ankle swelling by $30 \%$ and significantly decreased the number of synovial macrophages in type II collagen-induced arthritis in rats [44].

Apart from antibodies, chemokine antagonists or angiostatic chemokines may also be used as anti-rheumatic agents. For example, a 67-amino acid sequence of MCP-1, which acts as an MCP-1 antagonist in vitro, abrogated arthritis in MRL-lpr autoimmune mice [18]. A bioactive synthetic peptide derived from the angiogenesis inhibitor chemokine PF4 suppressed type II collagen-induced arthritis in mice [75].

\section{Conclusions}

In this review we have discussed the putative role of chemokines in RA. A number of $\mathrm{C}-\mathrm{X}-\mathrm{C}$ and $\mathrm{C}-\mathrm{C}$ chemokines are involved in the inflammatory and angiogenic events underlying the pathogenesis of arthritis. In addition, chemokine research has important clinical implications. For example, some of these mediators are detectable in the serum of RA patients and may eventually serve as useful laboratory markers of disease activity. Moreover, chemokine overproduction detected in RA and other forms of inflammatory arthritis may be therapeutically targeted with anti-inflammatory agents or cytokine inhibitors. In the next decade, it is likely that clinically available specific antagonists of chemokines or their receptors will be developed. Future directions in cytokine and chemokine research may also include somatic gene therapy.

Given the sometimes limited efficacy of currently used anti-rheumatic therapies, we must consider alternative strategies to treat RA patients. These approaches may include the ablation of inflammatory mediators including chemokines. Hopefully, the study of chemokines and their interactions with other components of the inflammatory network present in the inflamed synovium will lead to the development of specific immunomodulatory therapies that will prevent joint destruction and, thus, benefit RA patients. 
Acknowledgements. This work was supported by National Institute of Health grants AR-30692, AR-41492 and AI-40987 (A.E.K.), HL-02401 and HL-50057 (R.M.S.), HL-31693 (S.L.K.); SCOR grant IP50HL46487 (R.M.S. and S.L.K.); funds from the Veterans' Administration Research Service (A.E.K.); the Arthritis Foundation, Illinois Chapter Wolkonsky Award for Rheumatoid Arthritis research grant (A.E.K.); funds from Northwestern Memorial Hospital (A.E.K.); the Gallagher Professorship for Arthritis Research (A.E.K.); grants from the Hungarian National Scientific Research Funds no. T 013239 and F 025813 (Z.S.), and the Medical Research Council Fund no. T-05 314/96 (Z.S.)

\section{References}

1. Akahoshi T, Wada C, Endo H, Hirota K, Hosaka S, Takagishi K (1993) Expression of monocyte chemotactic and activating factor in rheumatoid arthritis. Arthritis Rheum 36:762

2. Bazan JF, Bacon KB, Hardiman G, Wang W, Soo K, Rossi D, Greaves DR, Zlotnik A, Schall TJ (1997) A new class of membrane bound chemokine with a CXC3 motif. Nature $385: 640$

3. Bedard PA, Golds EE (1993) Cytokine-induced expression of mRNAs for chemotactic factors in human synovial cells and fibroblasts. J Cell Physiol $154: 433$

4. Brennan FM, Zachariae CO, Chantry D, Larsen CG, Turner M, Maini RN, Matsushima K, Feldmann K (1990) Detection of interleukin 8 biological activity in synovial fluids from patients with rheumatoid arthritis and production of interleukin $8 \mathrm{mRNA}$ by isolated synovial cells. Eur J Immunol 20:2141

5. Castor CW, Smith EM, Hossler PA, Bignall MC, Aaron BP (1992) Detection of connective tissue activating peptide-III isoforms in synovium from osteoarthritis and rheumatoid arthritis patients: patterns of interaction with other synovial cytokines in cell culture. Arthritis Rheum 35:783

6. Castor CW, Andrews PC, Swartz RD, Ellis SG, Hossler PA, Clark MR (1993) The origin, variety, distribution, and biologic fate of connective tissue activating peptide-III isoforms: characteristics in patients with rheumatic, renal, and arterial disease. Arthritis Rheum $36: 1142$

7. Chen Y, Davidson BL, Marks RM (1994) Adenovirus-mediated transduction of the interleukin 8 gene into synoviocytes. Arthritis Rheum $37: \$ 304$

8. De Gendt CM, De Clerck LS, Bridts CH, Van Osselaer N, Stevens WJ (1996) Relationship between interleukin-8 and neutrophil adhesion molecules in rheumatoid arthritis. Rheumatol Int 16:169

9. Deleuran B, Lemche P, Kristensen M, Chu CQ, Field M, Jensen J, Matsushima K, Stengaard-Pedersen $\mathrm{K}$ (1994) Localisation of interleukin 8 in the synovial membrane, cartilage-pannus junction and chondrocytes in rheumatoid arthritis. Scand J Rheumatol $23: 2$

10. Drevlow BE, Lovis R, Hang R, Haag MA, Sinacore JM, Jacobs C, Blosche C, Landay A, Moreland LW, Pope RM (1996) Recombinant human interleukin-1 receptor type I in the treatment of patients with active rheumatoid arthritis. Arthritis Rheum $39: 257$

11. Endo H, Akahoshi T, Takagishi K, Kashiwazaki S, Matsushima K (1991) Elevation of interleukin-8 (IL-8) levels in joint fluids of patients with rheumatoid arthritis and the induction by IL- 8 of leukocyte infiltration and synovitis in rabbit joints. Lymphokine Cytokine Res $10: 245$

12. Evans CH, Robbins PD (1996) Pathways to gene therapy in rheumatoid arthritis. Curr Opin Rheumatol $8: 230$

13. Evans CH, Robbins PD (1997) Gene therapy in rheumatology. Rheumatol Eur 26 [Suppl 2] : 65

14. Fahey TJ III, Tracey KJ, Tekamp-Olson P, Cousens LS, Jones WG, Shires T (1991) Macrophage inflammatory protein 1 modulates macrophage function. J Immunol 148:2764

15. Feldmann M, Brennan FM, Maini RN (1996) Role of cytokines in theumatoid arthritis. Annu Rev Immunol 14:397

16. Feldmann M, Elliott MJ, Woody JN, Maini RN (1997) Anti-tumor necrosis factor- $\alpha$ therapy of rheumatoid arthritis. Adv Immunol $64: 283$

17. Golds EE, Mason P, Nyirkos P (1989) Inflammatory cytokines induce synthesis and secretion of gro protein and a neutrophil chemotactic factor but not beta 2-microglobulin in human synovial cells and fibroblasts. Biochem J 259:585

18. Gong JH, Ratkay LG, Waterfield JD, Clark-Lewis I (1997) An antagonist of monocyte chemoattractant protein 1 (MCP-1) inhibits arthritis in the MRL-lpr mouse model. J Exp Med 186:131

19. Hachicha M, Rathanaswami P, Schall TJ, McColl SR (1993) Production of monocyte chemotactic protein-1 in human type B synoviocytes. Arthritis Rheum $36: 26$

20. Harris ED (1990) Rheumatoid arthritis: pathophysiology and implications for therapy. N Engl J Med $332: 1277$ 
21. Hogan M, Sherry B, Ritchlin C, Fabre M, Winchester R, Cerami A, Bucala R (1994) Differential expression of the small inducible cytokines gro $\alpha$ and gro $\beta$ by synovial fibroblasts in chronic arthritis: possible role in growth regulation. Cytokine $6: 61$

22. Hosaka S, Akahoshi T, Wada C, Kondo H (1994) Expression of the chemokine superfamily in rheumatoid arthritis. Clin Exp Immunol 97:451

23. Isik FF, Rand RP, Gruss JS, Benjamin D, Alpers CE (1996) Monocyte chemoattractant protein-1 mRNA expression in hemangiomas and vascular malformations. J Surg Res $61: 71$

24. Jordan NJ, Watson ML, Yoshimura T, Westwick J (1996) Differential effects of protein kinase C inhibitors on chemokine production in human synovial fibroblasts. Br J Pharmacol 117:1245

25. Kasama T, Strieter RM, Lukacs NW, Lincoln PM, Burdick MD, Kunkel SL (1995) Interleukin-10 expression and chemokine regulation during the evolution of murine type II collagen-induced arthritis. $\mathrm{J}$ Clin Invest $95: 2868$

26. Koch AE, Kunkel SL, Burrows JC, Evanoff HL, Haines GK, Pope RM, Strieter RM (1991) Synovial tissue macrophage as a source of the chemotactic cytokine IL-8. J Immunol 147:2187

27. Koch AE, Kunkel SL, Harlow LA, Johnson B, Evanoff HL, Haines GK, Burdick MD, Pope RM, Strieter RM (1992) Enhanced production of monocyte chemoattractant protein-1 in rheumatoid arthritis. J Clin Invest $90: 772$

28. Koch AE, Polverini PJ, Kunkel SL, Harlow LA, DiPietro LA, Elner VM, Elner SG, Strieter RM (1992) Interleukin-8 as a macrophage-derived mediator of angiogenesis. Science 258:1798

29. Koch AE, Kunkel SL, Harlow LA, Mazarakis DD, Haines GK, Burdick MD, Pope RM, Strieter RM (1994) Macrophage inflammatory protein-1 alpha. A novel chemotactic cytokine for macrophages in rheumatoid arthritis. J Clin Invest $93: 921$

30. Koch AE, Kunkel SL, Harlow LA, Mazarakis DD, Haines GK, Burdick MD, Strieter RM (1994) Epithelial neutrophil activating peptide-78: a novel chemotactic cytokine for neutrophils in arthritis. J Clin Invest $94: 1012$

31. Koch AE, Kunkel SL, Shah MR, Fu R, Mazarakis DD, Haines GK, Burdick MD, Pope RM, Strieter RM (1995) Macrophage inflammatory protein-1 beta: a C-C chemokine in osteoarthritis. Clin Immunol Immunopathol $77: 307$

32. Koch AE, Kunkel SL, Shah MR, Hosaka S, Halloran MM, Haines GK, Burdick MD, Pope RM, Strieter RM (1995) Growth related gene product alpha: a chemotactic cytokine for neutrophils in rheumatoid arthritis. J Immunol 155:3660

33. Koch AE, Kunkel SL, Strieter RM (1995) Cytokines in rheumatoid arthritis. J Invest Med 43:28

34. Koch AE, Kunkel SL, Strieter RM (1996) Chemokines in arthritis. In: Koch AE, Strieter RM (eds) Chemokines in disease. RG Landes Company, Austin, pp 103-116

35. Kunkel SL, Lukacs N, Kasama T, Strieter RM (1996) The role of chemokines in inflammatory joint disease. J Leukoc Biol 58:6

36. Lebsack ME, Paul CC, Bloedow DC (1991) Subcutaneous IL-1 receptor antagonist in patients with rheumatoid arthritis. Arthritis Rheum $34:$ S45

37. Loetscher P, Dewald B, Baggiolini M, Seitz M (1994) Monocyte chemoattractant protein 1 and interleukin 8 production by rheumatoid synoviocytes: effects of anti-rheumatic drugs. Cytokine $6: 162$

38. Loetscher P, Uguccioni M, Bordoli L, Baggiolini M, Moser B, Chizzolini C, Dayer JM (1998) CCR5 is characteristic of Th1 lymphocytes. Nature $391: 344$

39. Lotz M, Terkeltaub R, Villiger PM (1991) Cartilage and joint inflammation: regulation of IL-8 expression by human articular chondrocytes. J Immunol 148:466

40. Mackay CR (1997) Chemokines: what chemokine is that ? Curr Biol $7:$ R384

41. Martin CA, Dorf ME (1991) Differential regulation of interleukin-6, macrophage inflammatory protein-1, and JE/MCP-1 cytokine expression in macrophage cell lines. Cell Immunol $135: 245$

42. Moreland LW, Baumgartner SW, Schiff MH, Tindall EA, Fleischmann RM, Weaver AL, Ettlinger RE, Cohen S, Koopman WJ, Mohler K, Widmer MB, Blosch CM (1997) Treatment of rheumatoid arthritis with a recombinant human tumor necrosis factor receptor (p75)-fusion protein. N Engl J Med $337: 141$

43. Narumi S, Tominaga Y, Tamaru M, Shimai S, Okumura H, Nishioji K, Itoh Y, Ikanoue T (1997) Expression of IFN-inducible protein-10 in chronic hepatitis. J Immunol 158:5536

44. Ogata H, Takeya M, Yoshimura T, Takagi K, Takahashi K (1997) The role of monocyte chemoattractant protein-1 (MCP-1) in the pathogenesis of collagen-induced arthritis in rats. J Pathol 182:106

45. Oppenheim JJ, Zachariae COC, Mukaida N, Matsushima K (1991) Properties of the novel proinflammatory supergene "intercrine" cytokine family. Annu Rev Immunol 9:617

46. Piechl P, Ceska M, Effenberger F, Haberhauer G, Broell H, Lindley IJ (1991) Presence of NAP-1/IL-8 in synovial fluids indicates a possible pathogenic role in rheumatoid arthritis. Scand J Immunol $34: 333$ 
47. Piechl P, Ceska M, Broell H, Effenberger F, Lindley IJ (1992) Human neutrophil activating peptide/interleukin 8 acts as an autoantigen in rheumatoid arthritis. Ann Rheum Dis 51:19

48. Qin S, Rottman JB, Myers P, Kassam N, Weinblatt M, Loetscher M, Koch AE, Moser B, Mackay CR (1998) The chemokine receptors CXCR3 and CCR5 mark subsets of T cells with a homing predilection for certain inflammatory sites. J Clin Invest 101:746

49. Rampart M, Herman AG, Grillet B, Opdenakker G, Van Damme J (1992) Development and application of a radioimmunoassay for interleukin-8: detection of interleukin- 8 in synovial fluids from patients with inflammatory joint disease. Lab Invest $66: 512$

50. Rankin ECC, Choy EHS, Kassimos D, Kingsley GH, Sopwith AM, Isenberg DA, Panayi GS (1995) The therapeutic effects of an engineered human anti-tumour necrosis factor alpha antibody (CDP571) in rheumatoid arthritis. Br J Rheumatol $34: 334$

51. Rathanaswami P, Hachicha M, Sadick M, Schall TJ, McColl SR (1993) Expression of the cytokine RANTES in human rheumatoid synovial fibroblasts. Differential regulation of RANTES and interleukin-8 genes by inflammatory cytokines. J Biol Chem 268:5834

52. Rathanaswami P, Hachicha M, Wong WL, Schall TJ, McColl SR (1993) Synergistic effect of interleukin- 1 beta and tumor necrosis factor alpha on interleukin- 8 gene expression in synovial fibroblasts. Evidence that interleukin-8 is the major neutrophil-activating chemokine released in response to monokine activation. Arthritis Rheum 36:1295

53. Recklies AD, Golds EE (1992) Induction of synthesis and release of interleukin- 8 from human articular chondrocytes and cartilage explants. Arthritis Rheum $35: 1510$

54. Robinson E, Keystone EC, Schall TJ, Gillett N, Fish EN (1995) Chemokine expression in rheumatoid arthritis (RA): evidence of RANTES and macrophage inflammatory protein (MIP)-1 beta production by synovial T cells. Clin Exp Immunol $101: 398$

55. Rot A, Hub E, Middleton J, Pons F, Rabeck C, Thierer K, Wintle J, Wolff B, Zsak M, Dukor P (1996) Some aspectos of IL-8 pathophysiology. III. Chemokine interaction with endothelial cells. J Leukoc Biol $59: 39$

56. Sato M, Miyazaki T, Nagaya T, Murata Y, Ida N, Maeda K, Seo H (1996) Antioxidants inhibit tumor necrosis factor-alpha mediated stimulation of interleukin-8, monocyte chemoattractant protein-1, and collagenase expression in cultured human synovial cells. J Rheumatol $23: 432$

57. Schall TJ (1991) Biology of the RANTES/SIS cytokine family. Cytokine $3: 165$

58. Schall TJ, Bacon K, Toy KJ, Goeddel DV (1990) Selective attraction of monocytes and T lymphocytes of the memory phenotype by cytokine RANTES. Nature 347:669

59. Schonbeck U, Brandt E, Petersen F, Flad HD, Loppnow H (1995) IL-8 specifically binds to endothelial but not to smooth muscle cells. J Immunol $154: 2375$

60. Seitz M, Dewald B, Gerber N, Baggiolini M (1991) Enhanced production of neutrophil-activating peptide-1/interleukin-8 in rheumatoid arthritis. J Clin Invest $87: 463$

61. Seitz M, Loetscher P, Dewald B, Towbin H, Rordorf C, Gallati H, Baggiolini M, Gerber NJ (1995) Methotrexate action in rheumatoid arthritis: stimulation of cytokine inhibitor and inhibition of chemokine production by peripheral blood mononuclear cells. Br J Rheumatol 34 : 602

62. Strieter RM, Polverini PJ, Kunkel SL, Arenberg DA, Burdick MD, Kasper J, Dzuiba J, Van Damme J, Walz A, Marriott D, Chan S-Y, Roczniak S, Shanafelt AB (1995) The functional role of the ELR motif in CXC chemokine-mediated angiogenesis. J Biol Chem 270:27348

63. Strieter RM, Kunkel SL, Shanafelt AB, Arenberg DA, Koch AE, Polverini PJ (1996) The role of C-X-C chemokines in the regulation of angiogenesis. In: Koch AE, Strieter RM (eds) Chemokines in disease. RG Landes Company, Austin, pp 195-209

64. Tanabe M, Ochi T, Tomita T, Suzuki R, Sakata T, Shimaoka Y, Nakagawa S, Ono K (1994) Remarkable elevation of interleukin 6 and interleukin 8 levels in the bone marrow serum of patients with rheumatoid arthritis. J Rheumatol $21: 830$

65. Taub DD (1996) C-C chemokines - an overview. In: Koch AE, Strieter RM (eds) Chemokines in disease. RG Landes Company, Austin, pp 27-54

66. Taub DD, Conlon K, Lloyd AR, Oppenheim JJ, Kelvin DJ (1993) Preferential migration of activated $\mathrm{CD} 4^{+}$and $\mathrm{CD}^{+} \mathrm{T}$ cells in response to MIP-1 $\alpha$ and MIP-1 $\beta$. Science $260: 355$

67. Unemori EN, Amento EP, Bauer EA (1993) Melanoma growth-stimulatory activity/GRO decreases collagen expression by human fibroblasts. Regulation by C-X-C but not C-C cytokines. J Biol Chem 268 : 1338

68. Villiger PM, Terkeltaub R, Lotz M (1992) Monocyte chemoattractant protein-1 (MCP-1) expression in human articular cartilage. J Clin Invest $90: 488$ 
69. Villiger PM, Terkeltaub R, Lotz M (1992) Production of monocyte chemoattractant protein-1 by inflamed synovial tissue and cultured synoviocytes. J Immunol 149:722

70. Waiz A, Burgener R, Car B, Baggiolini M, Kunkel SL, Strieter RM (1991) Structure and neutrophil-activating properties of a novel inflammatory peptide (ENA-78) with homology to interleukin 8. J Exp Med 174:1355

71. Walz A, Kunkel SL, Strieter RM (1996) C-X-C chemokines - an overview. In: Koch AE, Strieter RM (eds) Chemokines in disease. RG Landes Company, Austin, pp 1-25

72. Watson ML, Lewis GP, Westwick J (1988) Neutrophil stimulation by recombinant cytokines and a factor produced by IL-1 treated human synovial cell cultures. Immunology $65: 567$

73. Watson ML, Lewis GP, Westwick J (1989) PMN stimulation by factors from IL-1 treated human synovial cell cultures. Agents Actions 27:448

74. Wolpe SD, Cerami A (1989) Macrophage inflammatory proteins 1 and 2: members of a novel superfamily of cytokines. FASEB J $3: 2565$

75. Wooley PH, Schaefer C, Whalen JD, Dutcher JA, Counts DF (1997) A peptide sequence from platelet factor 4 (CT-112) is effective in the treatment of type II collagen induced arthritis in mice. J Rheumatol $24: 890$

76. Youssef PP, Haynes DR, Triantafillou S, Parker A, Gamble JR, Roberts-Thomson PJ, Ahern MJ, Smith MD (1997) Effects of pulse methylprednisolone on inflammatory mediators in peripheral blood, synovial fluid, and synovial membrane in rheumatoid arthritis. Arthritis Rheum 40: 1400 